\title{
Question-Negotiation and Information Seeking in Libraries
}

\begin{abstract}
Seekers of information in libraries either go through a librarian intermediary or they help themselves. When they go through librarians they must develop their questions through four levels of need, referred to here as the visceral, conscious, formalized, and compromised needs. In his pre-search interview with an information-seeker the reference librarian attempts to help him arrive at an understanding of his "compromised" need by determining: (1) the subject of his interest; (2) his motivation; (3) his personal characteristics; (4) the relationship of the inquiry to file organization; and (5) anticipated answers. The author contends that research is needed into the techniques of conducting this negotiation between the user and the reference librarian.
\end{abstract}

\section{Delbruck's Principle of LiMITED SLOPPINESS}

You should be sloppy enough so that the unexpected happens, yet not so sloppy that you cannot figure out what happens after it has happened.-in Eiduson, Bernice T. Scientists: Their Psychological World (1962), p. 126.

\section{$\mathrm{T}_{\mathrm{r}}$}

he MAJOR PROBLeM facing libraries, and similar information systems, is how to proceed from "things as they are now" to "things as they may be." It is an illu-

Mr. Taylor is Director of the Library at Hampshire College, Amherst, Mass. The work described here was accomplished at Lehigh University, while the author was Director of the Center for the Information Sciences, and was supported by grant from the Air Force Office of Aerospace Research, AFAFOSR-724-66. This paper is a summary of a report of the same title, issued as Report No. 3 (July 1967) in the Series, Studies in the ManSystem Interface in Libraries, published at Lehigh University. minating exercise to extrapolate from present technology to describe the library of the future. However, such exercises have little to say as to how to proceed from "now" to "then."1

There are two possible alternatives to this process of change, with a whole range of options. ${ }^{2}$ First the revolutionary concept: libraries will wither away and their place in the communications network will be taken by some new institutional form, probably imposed from the outside. The second one, an evolutionary development, is that libraries themselves will gradually make the transition.

The work described here is based on the second alternative. The objective was to examine and analyze certain relationships between library system and library user. It is hoped that this paper develops sufficiently fruitful generalizations, so that further investigations can start at a different level, with new assumptions. It

1 J. C. R. Licklider, Libraries of the Future (Cambridge: The M.I.T. Press, 1965).

2 Philip H. Ennis, "Technological Change and the Professions: Neither Luddite nor Technocrat," Library Quarterly, XXXII (July 1962), 189-98. 
is further hoped that, as a result of future investigations in this area, the evolution of libraries from passive warehouses to dynamic communication centers will be less traumatic and more effective.

This paper is not concerned with the usual library automation, although the effect that automation may have on the interface between user and system is recognized. In time, the automation of routine processes, i.e., order, catalog, and circulation control, after the bugs are worked out, will allow a different level of interaction. But routine automation is merely an extension of the control and warehousing functions of libraries. The work described here is an early effort to understand better the communications functions of libraries and similar types of information centers, because this is what libraries are all about.

Consequently this paper is concerned with two phases of this interface, which revolve around the process of negotiating the question. This act of negotiation usually takes one or both of these forms: (a) working through a human intermediary, i.e. the reference librarian; (b) self-help, by which the user himself attempts, often unsuccessfully, to sharpen his question by interacting with the library and its contents.

Reference librarians and information specialists have developed, both consciously and unconsciously, rather sophisticated methods of interrogating users. These methods are difficult to describe, indeed some believe they are indescribable. No such assumption is made here, in the belief that there are gross categories or levels of information which are consciously sought and received by the librarian in the negotiation process. We are dealing here of course with a very subtle problem-how one person tries to find out what another person wants to know, when the latter cannot describe his need precisely. There are a few good but unsystematic papers on the reference functions, but very little has been done of an analytical nature. ${ }^{3}$

In the self-help process, the user depends upon his own knowledge, frequently incomplete, of the system. It appears that there are a large number of users of information systems who, for a variety of reasons, will not ask a librarian for assistance. They develop their own search strategy, neither very sure of what it is they want nor fully cognizant of the alternatives open to them.

Both of these processes have some things in common: the development of a strategy of search, and frequently a change in the type of answer anticipated or acceptable as the search or negotiation continues. There is an implicit assumption in this paper, which intuitively seems valid. Most experimental work with retrieval systems and most attitudes toward reference questions look upon the inquiry and the relevance of answers as single events. This is mistaken. An inquiry is merely a micro-event in a shifting non-linear adaptive mechanism. ${ }^{4}$ Consequently, in this paper an inquiry is looked upon not as a command, as in conventional search strategy, but rather as a description of an area of doubt in which the question is open-ended, negotiable, and dynamic. ${ }^{5}$

The first part of the paper discusses and analyzes the negotiation process as practiced by reference librarians and information specialists. The author is in-

\footnotetext{
${ }^{3}$ M. Francillon, "Information Retrieval: A View from the Reference Desk," Journal of Documentation, XV (December 1959), 187-98; Margaret K. Goggin, ed., "Current Trends in Reference Services," Library Trends, XII (January 1964); Ellis Mount, "Communication Barriers and the Beference Question," Special Libraries, LVII (October 1966), 575-78.

4D. M. Mackay, "Operational Aspects of Some Fundamental Concepts of Human Communication," Synthese, IX (Issue 3, No. 3-5, 1954), 182-98.

${ }^{5}$ L. B. Doyle, "Is Relevance" an Adequate Criterion in Retrieval System Evaluation," in American Documentation Institute, 26th Annual Meeting, October 1963, Automation and Scientific Communication, Part II, 199200; R. S. Taylor, "The Process of Asking Questions," American Documentation, XIII (October 1962), 39196.
} 
debted to a number of professionals who subjected themselves to taped interviews ranging in length from sixty to ninety minutes. The interviews were limited to special librarians and information specialists for several reasons. ${ }^{6}$ First, they are usually concerned with substantive questions. Second, their inquiries usually come from highly motivated and critical people who have an idea what is acceptable as an answer. Third, to find material, the librarian must understand and therefore must negotiate the question. In contrast, public and academic librarians, because of the nature of their clientele and institutions, have educational responsibilities and staff restrictions which limit their response to inquiry. One special librarian pointed out:

The levels of frustration in using libraries are awfully high for most people. It's amazing, as hard as we work at making ourselves popular with these people, we still have them come in and stand diffidently at our desk and say, "Well, I don't want to interrupt, but . . ." To which I reply, "If you don't interrupt me I don't have a job." But it's amazing how people can't get over this. I think it would be a study in itself, that we grow up in school libraries, public libraries, and college libraries, generally where this kind of service is not provided. Consequently you are conditioned to feeling that the library is a place you almost have to drag something out of. The library is almost the last place they want to go, because they've been conditioned. ${ }^{7}$

The interviews were open-ended and unstructured. ${ }^{8}$ They were designed to

\footnotetext{
${ }^{6}$ In this report, the designations "reference librarian," "librarian," "information specialist," and "subject specialist" are used interchangeably. There are differences. In this report, however, these terms are used merely to identify the person negotiating the question, in contrast to the "inquirer," who poses the questions and requires information in some form as an answer.

${ }^{7}$ Unacknowledged quotations in this paper are from the taped interviews with reference librarians and information specialists. It was mutually agreed that such quotations would be anonymous. Minor editing has been done for clarity only.

${ }^{8}$ Stanley L. Payne, The Art of Asking Questions (Princeton, N.J.: Princeton University Press, 1951); Stephen A. Richardson, et al., Interviewing, Its Forms and Functions (New York: Basic Books, 1965).
}

elicit three things, described in the librarian's own words:

1. What categories of information does a librarian attempt to obtain from an inquirer?

2. What is the role of system file organization in the negotiation process?

3. What kinds of answers will inquirers accept and what influence might this have on the negotiation process?

\section{Question Negotiation by Librarians}

Without doubt, the negotiation of reference questions is one of the most complex acts of human communication.' In this act, one person tries to describe for another person not something he knows, but rather something he does not know. Quantitative data about this process is non-existent. In spite of its complexity, however, it is possible to say certain things about it and to form a gross classification of the process. This is a first necessary step toward a basis for valid observation and the statement of testable hypotheses.

It is worthwhile in this consideration of the negotiation process to attempt to understand what a question is. Although reference librarians and other "question negotiators" count what are called "questions," this is not really what this paper is concerned with. Let us attempt to reconstruct in general terms this negotiation process, that is, as it pertains to the interaction between an inquirer and an information specialist.

The inquirer has what D. M. Mackay calls "a certain incompleteness in his picture of the world-an inadequacy in what we might call his 'state of readiness' to interact purposefully with the world around him," 10 in terms of a par-

${ }^{\ominus}$ N. D. Belnap, Jr., An Analysis of Questions: Preliminary Report. Document TM-1287 (Santa Monica, California, 1963); R. F. Simmons, "Answering English Questions by Computer: A Survey," ACM Communications, VIII (January 1966), 53-70.

${ }^{10} \mathrm{D}$. M. Mackay, "What Makes a Question," The Listener, LXIII (May 5, 1960), 789-90. 


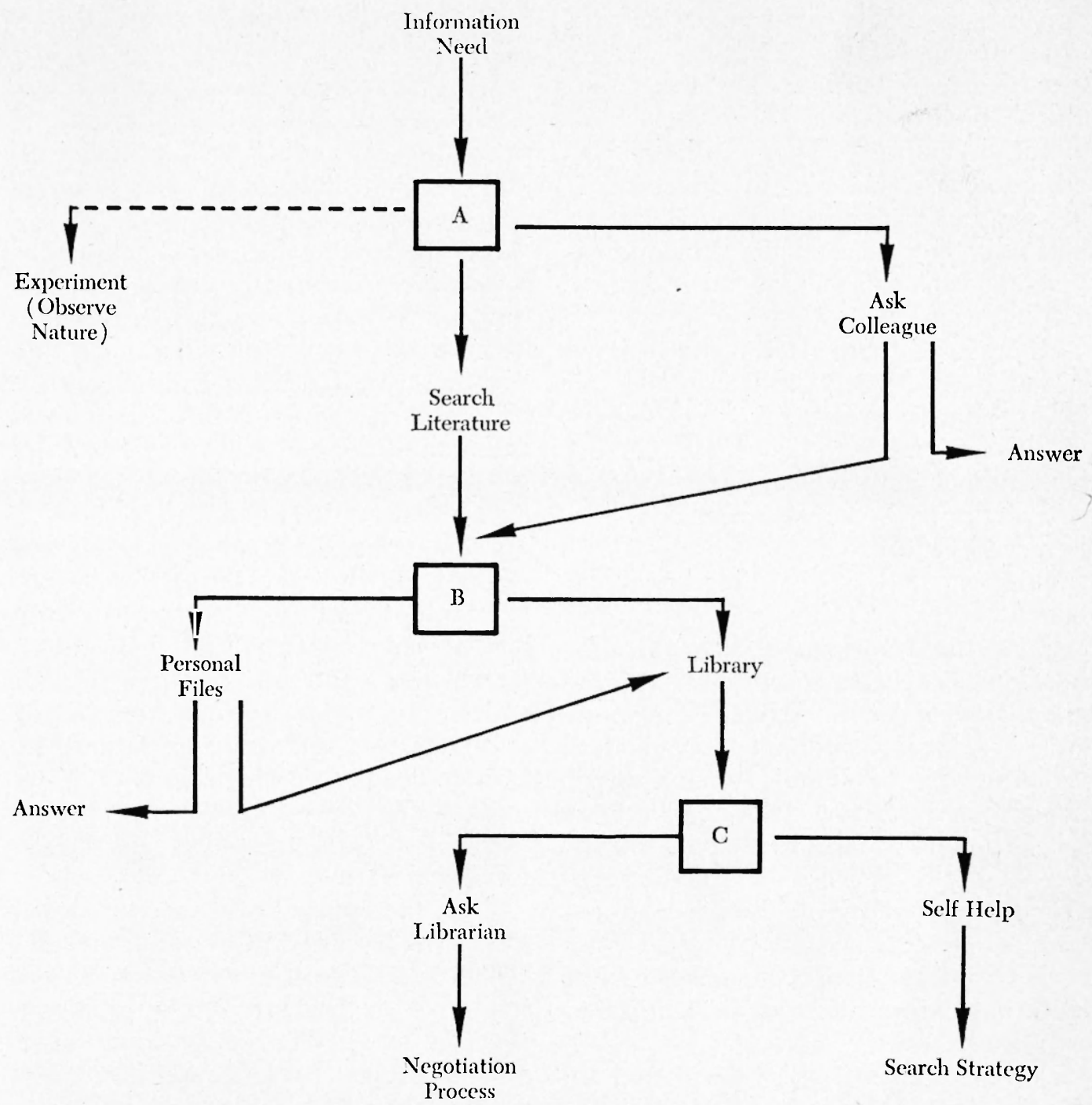

Fic. 1. Prenegotiation decisions by the inquirer.

ticular area of interest. He comes to the library or information center as one of several possible alternatives, for information to fill out "his picture of the world." These alternatives themselves pose an important problem, illustrated in Figure 1.

In Figure 1 , at decision point $\mathrm{A}$, the inquirer decides whether to discuss his problem with a colleague or to go to whatever literature or information center may be available. Before he disturbs a busy colleague, he is likely to make a minimum search of his own files. This will happen only, however, if he has analyzed his "inadequacy" sufficiently to be able even to look through his own files.

He also makes a second decision ( $\mathrm{B}$ in Figure 1): to go to the library or information center. This is an important choice and reflects a number of factors: previous experience, environment (is this an accepted procedure in his activity?), and ease of access. Studies of information-seeking behavior indicate, for example, that "ease of access" to an information system is more significant than 
"amount or quality of information" retrievable. ${ }^{11}$

At decision point $\mathrm{C}$ he makes another choice of paths: $(a)$ to ask an information specialist; or $(b)$ to help himself. Most important in this decision is the inquirer's image of the personnel, their effectiveness, and his previous experience with this or any other library and librarian.

All three of these decisions will have an influence, largely undetermined, on the negotiation process. It is not the intent of this paper to do more than list these prenegotiation choices as forming part of the context and background for the process itself.

Assuming that the inquirer has made these choices and has arrived at the desk of the information specialist, he then specifies in some form what it is he hopes to find out. "Arrived" can mean any of several communication modes: by letter, by telephone, or by direct face-to-face interview. It is at this point that negotiation begins. Before consideration of this process, it is first necessary to discuss various levels of questions. In general we can describe four levels of information need and the configuration of question which represents each level. ${ }^{12}$

1. First of all, there is the conscious or even unconscious need for information not existing in the remembered experience of the inquirer. It may be only a vague sort of dissatisfaction. It is probably inexpressible in linguistic terms. This need (it really is not a question yet) will change in form, quality, concreteness, and criteria as information is added, as it is influenced by analogy, or

\footnotetext{
${ }^{11}$ Victor Rosenberg, "The Application of Psychometric Techniques to Determine the Attitudes of Individuals Toward Information Seeking," Report No. 2 Studies in the Man-System Interface in Libraries (Bethlehem, Pennsylvania: Center for the Information Sciences, Lehigh University, July 1966).

${ }^{12}$ James W. Perry, Defining the Query SpectrumThe Basis for Designing and Evaluating Retrieval Methods (n.p., 1961 [mimeo.]); Taylor, op. cit.
}

as its importance grows with the investigation.

2. At the second level there is a conscious mental description of an ill-defined area of indecision. It will probably be an ambiguous and rambling statement. The inquirer may, at this stage, talk to someone else to sharpen his focus. He presumably hopes that two things will happen in this process: $(a)$ his colleague will understand the ambiguities; and $(b)$ these ambiguities will gradually disappear in the course of the dialogue.

3. At this level an inquirer can form a qualified and rational statement of his question. Here he is describing his area of doubt in concrete terms and he may or may not be thinking within the context or constraints of the system from which he wants information. By the way, he may view the librarian as part of the system at this level, rather than as a colleague. This distinction is important. As one interviewed librarian said: "For most people, I am the information system."

4. At the fourth level the question is recast in anticipation of what the files can deliver. The searcher must think in terms of the organization of particular files and of the discrete packages available-such as books, reports, papers, drawings, or tables.

These four levels of question formation shade into one another along the question spectrum. They are stated here only as convenient points along a continuum. They may be outlined as follows:

$\mathrm{Q}_{1}-$ the actual, but unexpressed need for information (the visceral need);

Q - the conscious, within-brain description of the need (the conscious need);

$\mathrm{Q}_{3}$-the formal statement of the need (the formalized need);

$\mathrm{Q}_{4}$-the question as presented to the information system (the compromised need). 
Unless the inquirer knows the information specialist well, he is inclined to pose his first question in positive and well-defined terms, even to the point of specifying a particular package $\left(Q_{4}\right)$. If the specialist is accepted as a colleague, the negotiation process can start earlier and be much more fruitful. An important necessity for such acceptance appears to be subject knowledge. As one information specialist put it: "A person with a technical background will handle a technical subject in less than half the time and with more competent and thorough results." This is where the process of negotiation starts. The compromised question $\left(Q_{4}\right)$ is the information specialist's business, the representation of the inquirer's need within the constraints of the system and its files. The skill of the reference librarian is to work with the inquirer back to the formalized need $\left(Q_{3}\right)$, possibly even to the conscious need $\left(Q_{2}\right)$, and then to translate these needs into a useful search strategy.

This is a directed and structured process, although there are of course many different styles and many levels of competence and knowledge on the part of both librarian and inquirer. There are certain obvious traits which will help the librarian: empathy, sense of analogy, subject knowledge, and knowledge of files, collection, and clientele. ${ }^{13}$

${ }^{13}$ Francillon, op. cit.

FIG. 2. Schematic representation of communications between two friends over time.

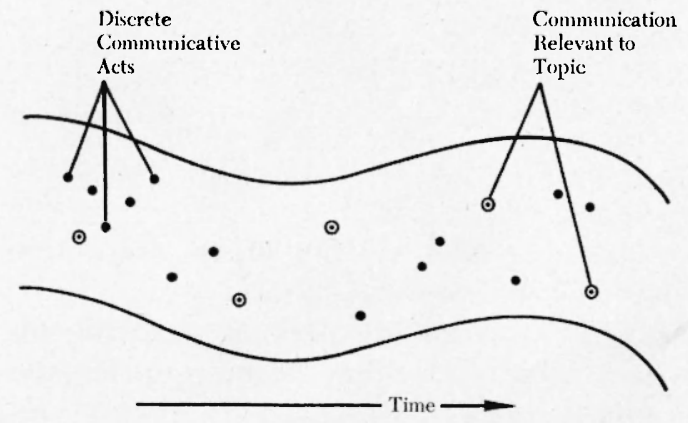

-The negotiation process is a form of communication. It is illuminating to contrast it with normal conversation, in which one person finds out in random fashion about another's interest. Figure 2 shows the stream of communicative acts on a variety of subjects between friends over a period of time. However, embedded in this conversation are elements of a subject of interest, which one person is communicating randomly to his friend. Communicative acts are shown by a dot; those which are relevant to the subject are circled.

In contrast, the negotiation process must compress both the boundaries of the interview and the time span. More information must be communicated in less time. This requires both direction and structure on the part of the information specialist. Figure 3 illustrates this compression, where relevant communicative acts are much more frequent.

From the interviews with librarians and information specialists there appear to be five filters through which a question passes, and from which the librarian selects significant data to aid him in his search. It is the structure of these filters, modified for the specific inquiry, that provides the compression of subject and time illustrated in Figure 3. These five general types of information necessary for the search definition are not mutually exclusive categories. The listing is approximately in order of occurrence, although they may occur simultaneously, i.e., relevant data for several filters may be embedded in a single statement by the inquirer.

They may be briefly stated as follows:

1. determination of subject;

2. objective and motivation;

3. personal characteristics of inquirer;

4. relationship of inquiry description to file organization;

5. anticipated or acceptable answers.

The problems associated with these "filters" are well known, even obvious, 


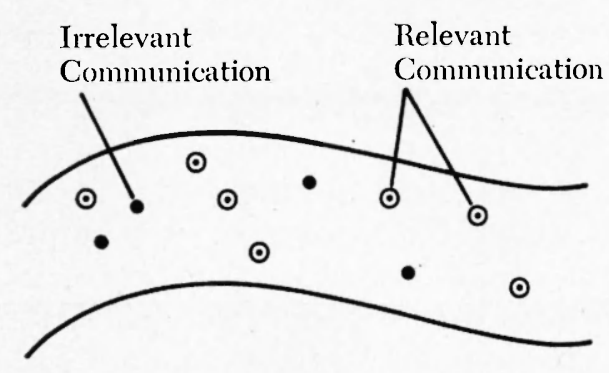

FIc. 3. Schematic representation of communication between incuirer and librarian during negotiation process.

to active librarians and information specialists. They have not been put together in rational form before.

\section{Determination of Subject}

Determination of the limits and structure of the subject of the inquiry comprise the content and aim of the first filter. The information culled at this level of negotiation is of course closely intertwined with that of the second filter (the objective and motivation behind the inquiry). However, the two filters appear to have a sufficiently different function and necessary style of negotiation to require separate consideration for each.

At the first pass the primary purpose of negotiated subject definition is to provide some general delineation of the area: from biomedicine to genetics to the genetic code in DNA. Continued dialogue on the ramifications and structure of the subject will define, expand, narrow, and qualify the inquiry.

$\mathrm{X}$ said he was interested in "contact terminals." Well, that's rather a vague term, and it probably took me a few minutes to find out what he meant by that. He might not even have started with that terminology. He meant "binding post" type of terminals. I probably asked him a question like: "Do you mean the type of spring terminals that are used in jacks, plugs and jacks?" He said, "No," and probably then said something about "binding posts." And I remarked "Oh, you mean soldered terminals." He probably replied, "No, that's where the contact comes into it, I mean the wrapped type." And so after a few exchanges like that, I would have gotten a picture in my mind as to what he was talking about. This is where my practical experience in radio engineering is helpful, because I can visualize these things.

At some stage, depending on the state of other relevant categories of information, it may be necessary to call a halt to this initial phase, in order to allow the librarian to make a brief search to determine the extent of the subject. He can then come back to the inquirer with "Is this what you mean?" or "Is this in the ball park?" From discussion in answer to these questions, the subject is further limited and qualified. This form of dynamic interaction may continue for some time, until the librarian is satisfied he knows what is wanted.

Engineer X will come in and say "Gee, I have these three references on subject $A$. I've got all the ones I know about. Are there any more?" He may just stop in passing. This may develop into a major project, just because the man is so busy, he is not aware of the vast amount of information available to him. Once the subject is defined, we define the peripheral areas that may bear upon this. We inform him of our basic search strategies so he feels he is part of the effort. And we inform him how he in turn can interact with us, depending on the time constraints. If it is a long term project, he will receive in the normal course of his work material we may not be aware of. In turn we ask that he input these data to us. And if it becomes necessary for one of our people to go to his office and physically go over and read some of the more important papers on the subject, we will do this. So there is a continuous interaction between the people in the information research group and the scientist and engineer asking for the material.

The fact that they write the question doesn't help one bit. We think if it's written it's clear. You know "put it in writing." But you get no feedback with writing. It's the dialogue, the feedback, that is the important 
thing. For the librarian, the important thing is this awareness of the fact that you will need feedback in order to make sure of what you've got. You have to have this suspicion-a sensing of when it is you know what it is the inquirer wants, and when it is you are sure he has got it clear, and when it is you are not sure.

\section{Motivation and Objective OF THE INQUIRER}

The second filter or category of information negotiated is probably the most critical: Why does the inquirer want this information? What is his objective? What is his motivation? This requires subtlety in negotiation, but usually has a high payoff in subject definition. It further qualifies the subject, or may even alter the entire inquiry. It also offers an opportunity to ascertain $\checkmark$ the point of view and influence the size, shape, and form of possible answers. Most of the librarians interviewed felt strongly that this type of question was critical to the success of any negotiation and consequent search. In those instances where this is not the case, the librarian's approach is that the inquirer (a) knows what he wants, (b) knows more than the librarian, and ( 3 ) is aware of the search strategies necessary to satisfy his need. None of these assumptions appear to be wholly valid.

Unless you are sure what the why is, you can never be sure what it is the person really wants. What's he going to do with the information .. We can't help him unless we understand his needs as well as he does.

It is an obvious truism to every librarian who works at an information or reference desk that inquirers seldom ask at first for what they want. When they reach the point of confessing, "But this is really what I want to know . ...," the acute librarian knows he is over a major hurdle.

Inquirers frequently cannot define what they want, but they can discuss why they need it. Consequently they are in- clined to ask very specific questions, as if they were ashamed to hold up their ignorance for everyone to see. These may include an innocent and unambiguous request for a directory address, which develops into a search on molds; a request for a copy of Aviation Week which turns into a basic and broad company proposal on commercial aviation; an inquiry to verify if there is a place called $\mathrm{P}$, which turns into a search for information on rat repellants. In these cases, as one interviewee pointed out, "My function is to help him decide what it is he wants."

The first step is to be eternally suspicious and the realization that in most cases they simply don't tell you what it is they really need. I think this is a matter of human communication-that we need the dialogue to frame up what we are after. I find this is true even in the simplest questions. There is that eternal suspicion that what they ask is probably not what they really want.

\section{Personal Background of the Inquirer}

The third level or category of information necessary in the negotiation process has to do with the personal background of the inquirer. What is his status in the organization? Has he been in the library before? What is his background? What relationship does his inquiry have to what he knows? What is his level of critical awareness? Answers to these types of questions have relevance to the total negotiation process. It may well determine the urgency, the strategy of the negotiation, the level of any dialogue, and the critical acceptance of search results. In short, it is the context, the environment for the negotiation process. It determines what questions should and may be asked.

Because we get to know our clientele personally, we know the type of response they need and require. We know whether a person is a thorough individual, or a less thorough one. In the latter case, it may be somewhat frustrating at times when you 
know you haven't gone far enough, yet they are satisfied.

Have I worked with him before? This makes a great deal of difference. If he is an old timer and I've worked with him before, I know pretty well what steps I can take in negotiating the question. If he is a stranger, or relative stranger to the information service, it presents a problem to me. Some of the questions I might ask are: What group are you working with? Who is your leader? Where he is situated in the organization is important. His status. Whether he is at ease or not. Sometimes we get people who feel very inadequate in coming to the library. They may come to us as a last resort, not knowing what they are getting into. They may feel that they are exposing themselves to someone looking over their shoulder. That is a position we don't want them to feel in.

There are many problems in this facet of negotiation. An instance cited by one interviewee is when an inquirer, who may be in his own right a highly competent researcher, is used as a high level messenger by, for example, the vice president for research. It is at this point, as the librarian pointed out, that experience and personal knowledge of the organization and people become important. The "messenger" frequently may not know the background and motivation for the inquiry. It is here that the librarian must make some educated guesses and associations based on experience. $\mathrm{He}$ must in some way bring the vice president into the dialogue, without undermining the reputation of the "messenger."

\section{RELATIONSHIP OF INQUIRY \\ Description to File Organization}

An information specialist or a reference librarian is an intermediary, an interlocutor, between the inquirer and the system. As such, the negotiation process not only provides him with a substantive description of the inquiry, but also supplies him clues for devising his search strategy. He becomes a translator, in- terpreting and restructuring the inquiry so it fits the files as they are organized in his library. ${ }^{1+}$ In the symbolism discussed earlier, he must construct a $Q_{4}$, or a set of $Q_{4}$ 's, so that the total system can be searched efficiently.

The inquirer will state briefly his problem over the phone. This is not enough so we go to him. We very likely do not discuss the specific problem but rather the relationship of the problem to the work he is doing. How does it tie in? We work from the general to the specific. He will often use a blackboard. What are the limits of the problem? In many cases we redefine the approach because he isn't familiar with the search strategy. So we redefine the problem to match the search strategy necessary. The inquirer is usually not aware of the sources available to him.

If we view the negotiation process as a "game of chess" as one librarian suggested, the librarian has a tremendous advantage. $\mathrm{He}$ is the one who knows the rules of the game; the inquirer doesn't. The "rules of the game" are the organization, structure, associations, and specific peculiarities of the files. The quotation above hints this: "We redefine the problem to match the search strategy." The implications of such a statement, if taken at face value, can have the effect of redefining librarianship.

It should be understood that the "files" refer not only to the catalogs, indexes, abstracts, and other standard files of the library. There is also the "who knows what" file, not on cards but in the librarian's memory. There are special files: previous requests, news notes, recent items read, the unstructured notes (or pieces of paper napkins) in the librarian's desk drawer. There is the sense, or activity, of building the inquiry into the system-the system including the information specialist and all the relevant files.

${ }^{14}$ Susan Artandi, "The Searchers-Links Between Inquirers and Indexes," Special Libraries, LVII (October 1966), 571-74. 
Referring people to other people is one of the methods we use. But before referring them, we ask "Whom have you talked to? Are you working by yourself or with others? Do you know X? Do you want to talk to $\mathrm{X}$, or should we?" You see, we don't want to go charging off in all directions, duplicating effort.

As much as possible, the librarians interviewed also tried to elicit from the inquirer any stray bits of information from his specialized knowledge that would give clues in support of a search strategy.

One of the standard qeustions we ask: "To your knowledge what will probably be the most fruitful area in which to search?" This opens up some leads ... often, he will say something like, "Well, I think there was a Proceedings of the IEEE about 1963 and I thought I saw something in there. Maybe that will give you a lead." In this particular case his hint was sufficient to open up the problem for us.

What the inquirer is saying is "Here is a paper. I'd like ones similar to it, or similar to it in this specific way."

\section{What Kind of Answer WiLl THE INQUiRer ACCEPT?}

When an inquirer approaches the reference desk, he has some picture in mind as to what he expects his answer to look like, i.e. format, data, size, etc. ${ }^{15}$ The problem of the inquirer's acceptability of an answer is an important filter in the process of answering inquiries. One of the results of the negotiation process is to alter the inquirer's a priori picture of what it is he expects. This picture is altered as the inquirer changes his question in response to feedback, as he becomes aware of the capabilities of both the library and the librarian, as he changes his search strategy in the negotiation process, and as he is forced in

\footnotetext{
1. Caroline E. Hieber, "An Analysis of Questions and Answers in Libraries," Report No. 1, Studies in the Man-System Interface in Libraries (Bethlehem, Pennsylvania: Center for Information Sciences, Lehigh University, June 1966).
}

the negotiation process to place limits of time and size on his inquiry.

The sense of urgency in the inquiry definitely has an influence on the type of answer expected.

The inquirer may say "I need this in 30 minutes." By doing so he has pretty well determined what form he will accept and what questions I can ask.

Whether or not the inquirer is asking for information in his own specialty will shape the kind of answer useful to him.

If a person is asking for a search in his own field, then you can sit down and talk to him. If he is asking in a field peripheral to his interest, then he has probably been asked to express an opinion on something. He doesn't want a search, but rather something limited, for example a review or a state-of-the-art paper.

Undoubtedly the subject field of the library and its clientele has a bearing on the type of answer expected, in ways we do not even know about yet. For example, in the law ${ }^{16}$ it appears that the questions are very precise, but the answers are less precise. This is due to the nature of precedence in the law, in which a law, a court ruling, or an administrative regulation might be pertinent to a specific case, and are the only answers available. They don't however answer the question. Training in the law appears to make a difference. As one librarian put it: "I can almost tell the law school by the type of question."

One of the nagging problems in the delivery of answers seems to be the degree of evaluation the information staff can and should make. There are of course a variety of factors at work here: the librarian's own capability; the inquirer's attitude; and the available time. One interviewed librarian described the problem as follows:

Now the next level beyond this is one in which we have hardly done anything at all,

${ }^{16}$ Lord Radcliffe, "How a Lawyer Thinks," Lancet, CCLXX (January 1956), 1-5. 
primarily because we don't have the manpower. But I think it is probably the most important. . . . That is to make an evaluation of these materials. Just to hand someone a batch of raw abstracts is not enough; or even a list of numbers; paper A says the property equals this, paper B says it's that, and so on. Well, if they don't agree, shouldn't someone read the papers, and decide what were the experimental techniques, and give these a weight? That is, this is the most significant number, or the most valid number, or this is a significant average. We have just not been able to do it except in a few rare instances. Now the hope had been-when I say "hope" I don't mean only ours, but from the top of the Research and Engineering Department down - that, if we gave the individual chemist or engineer these other materials, he would do this evaluation. The evidence is that he doesn't do it. I would say only $1 \%$ actually do it. The others will take the first number at the top of the pile, some will average all the numbers, some will apparently take the number that fits their number best. You know, it's the human problem.

Perhaps the most important obstacle to evaluation by the librarian is the sense of puritanism on the part of both librarians and management who believe, for ethical rather than economic reasons, that everyone should do his own work. Such an ethos is at odds with the sense of service in librarianship, with the requirements of management for the best information as soon as possible, and with the growing complexity of libraries in a "data-rich civilization."

\section{The Information Seeking Strategies OF USERS}

This paper makes an assumption which seems intuitively valid. In the self-help process, i.e. when an inquirer attempts to find information in his own way, we view the inquiry not as a command, but rather as an adaptive self-organizing system in which the question is open-ended and dynamic. In fact, as will be illustrated, the inquirer's original question may change during the search, as he adapts to the feedback of the search process.

Let us discuss briefly commands and questions, for an understanding of the difference between them is critical for the development of truly interactive systems. ${ }^{17}$ A command basically denotes the request for a specific item or specific subject combination which the inquirer has already assumed will satisfy his need. Whether his assumption is valid or not has been discussed before. For the moment we accept its validity. In response to his command, the inquirer is delivered, or he locates, a specific package. Here the process ends, and he is satisfied (by definition).

Libraries and other information systems have been developed and operated on these premises. However, one may suspect that the rise of reference services -historically, a rather recent development-and the care lavished upon indexing, cataloging, and classification schemes indicates a feeling that traditional "command" systems must have some form of feedback built into them.

There are of course many mechanisms by which classificationists, index designers, and other information system developers have attempted to develop strategies and alternatives for the inquirer. For the inquirer, however, these are frequently oversophisticated, at least in the display forms in which they presently exist. The inquirer is only concerned with getting an answer, not with system niceties. Nor is he interested in learning and maintaining currency with a system in which only a very minor part has relevance to him. An analogy may be made to the myriads of directional signs on an urban freeway. The signs seem to be designed for the benefit of natives and not strangers. Though the principle remains the same, the results

\footnotetext{
17 D. M. Mackay, "Informational Analysis of Questions and Commands," in Information Theory, C. Cherry, ed. (London: Butterworths, 1961), p. 469-76.
} 
of a wrong decision in the latter case are apt to be somewhat more catastrophic, in the immediate sense at least.

There really has been little empathy for the unsophisticated (i.e. non-native) user. Within the conventional information system, the signs offered the inquirer pose too many alternatives without specification as to where each may lead or what each will do for the inquirer. It may be that better forms of display and interrogation by the system, in an interactive sense, can provide more adaptive interfaces.

The concept of the interface, in this context, must be extended beyond its usual meaning of a physical surface or panel of control buttons and knobs. It includes here not only the physical problems, e.g. ease of use, but also the subtle and personal interrelationship, however primitive this knowledge may be at present, between user and recorded knowledge.

Within this context, the question, as contrasted to the command, can be better understood. In the symbolism developed above, the command is $Q_{4}$, the question compromised by the rigidities of the system and by the specific need assumed by the inquirer. However the question moves back toward $Q_{3}$ and even toward $Q_{2}$. It is ambiguous, imprecise, and requires feedback from the system, or from a colleague, in order to provide an acceptable answer. This approach, without intruding on epistemological grounds, may also give clues to a better understanding of the differences between information and knowledge.

As a first pass at understanding information-seeking, approximately twenty undergraduate students in a course, "The Information Sciences" at Lehigh University were asked to report on the process resulting from a self-generated information need. Four of these searches are discussed here. The project had two purposes. First, from a pedagogical standpoint, it was intended to create an awareness in the students of themselves as information-seekers: the decisions they make; the sources they use; the complexities and failures of the systems they encounter; and the ambiguities and strategies of their question-asking processes. Second, it was hoped that some gross generalizations could be made of this process, notwithstanding the open-endedness and uncontrolled nature of the project.

The students were first asked to read the section on "Human Search Strategies," from the report of the Advanced Information Systems Company. ${ }^{18}$ This was done to give them some feel for the scope and nature of the problem. They were then asked, following class discussion, to write a description of their search for specific information in any topic of interest to them at that time. This approach was felt to be better than one based on artificially generated searches, because (a) they could draw on their own experience and interests, and (b) they could determine when they had an acceptable answer. They were allowed to use any sources they wished and to ask advice from anyone. They were instructed to conduct the search in whatever way seemed easiest and most efficient. They were not restricted to the library, although they were requested to use the library somewhere in their search.

The following instructions were given orally and were briefly discussed:

1. Do not attempt to describe every motion or every decision in full detail. However, please pick out what, in your judgment, are some of the more important or significant decision points and record those completely.

2 . In the beginning analyze your question: What do I know already? What will I accept as an answer? Note that your question, and your criteria of an-

\footnotetext{
18 Advanced Information Systems Co. Report on the Organization of Large Files with Self-Organizing Capability (Los Angeles: 1961).
} 
swer acceptability, may change as the search progresses.

3. Analyze possible search strategies and estimate probability of success. Note that new strategies may appear in the search process, or may be altered in a variety of ways.

4. The following activities are significant:

$a$. the original question and any reevaluation of it;

$b$. interrogation of a source, both human and printed or graphic;

c. decisions to try a new strategy or to re-evaluate the strategy;

d. significant results of an interrogation, including important clues;

$e$. memory or store, i.e. partial data thought pertinent to the search, which you hold in "memory," or record in some fashion;

f. "dead end" of a search path, in which you could (1) go to new strategy, (2) re-evaluate question, or (3) consider the whole question not worth the trouble.

There are several observations and a few generalizations that can be extracted from the resulting search strategies.

1. All searchers used some human intermediaries, fellow students, or reference librarians, to give them clues or guidance.

2. No student thought in terms of a library strategy, that is, to view the total collection as a source and then devise one or several approaches to it. All of them however used certain library mechanisms of a strategic nature:

a. To use the classification schedule as a means of searching:

None of the books indicated looks promising. However they all have the same catalog number (510.7834). I'll look in the stacks at that number and see if any of the books are promising.

b. To use the Subject Catalog (the library used a divided catalog).

c. To search the Subject Catalog be- yond the original subject heading for phrases, etc.

Under CURVES there were nine books. ... So I was about to look at SURFACES when I noticed a card saying CURVES ON SURFACES.

3. Most of the inquiries posed could not be answered by any single book or paper. They represent, however, questions of the type that users (in this case, engineers) wish to have answered:

No. 1: What is the relationship for the rate of gaseous molecular bombardment of the walls of the gases container?

No. 2: What is micro-programming?

No. 3: What is a concise definition of "Gaussian Curvature?"

No. 4: How does the Philco $\mathrm{F}_{10}$ differential amplifier operate in the model 228 digital memory unit?19

4. The searchers generally made good use of tables of contents and indexes of single books examined. When they did not, they made poor judgments as to the usefulness of specific chapters to their inquiry.

5. Answers usually do not come in neat little packages in answer to a specific question of the type posed here. One, for example, had to put his answer together from seven different sources, albeit in a single book.

6. When available information sources do not provide enough information for an acceptable answer, it is necessary to alter the question. As the student with Question No. 4 found out:

The question will have to be generalized because specific data supply is exhausted. How is a general transistor differential amplifier analyzed?

7. For the type of questions posed, there is a great deal of noise in library catalogs, particularly in the Subject section. This may be characteristic of aca-

\footnotetext{
1* J. S. Green, "GRINS, an On-Line Structure for the Negotiation of Inquiries," Report No. 4, Studies in the Man-System Interface in Libraries. (Bethlehem, Pennsylvania; Center for Information Sciences, Lehigh University, June 1966).
} 
demic libraries, whose collections are based on quantity rather than quality.

The results seem to support the belief that the inquirer's interaction with a library or information system has certain similarities to the negotiation process. If this belief has validity, it means that libraries are very frustrating to use and that library systems need considerably more experimental work to enhance this interface between user and library.

\section{Summary and Conclusions}

What has been gained by this investigation? Or does it merely reiterate what is already known? Is this, as someone has said about psychology, an elaboration of the obvious? In part, it certainly has been an elaboration of the obvious. But it has been more. It has attempted, by restructuring the obvious, to open up new ways of looking at libraries. The whole purpose has been, by organization and structure, to allow the reference and searching processes to be seen from a point closer to actual fact. This was done in the hope that a more intensive study of this process will result, and that elements could be isolated for fruitful analysis and eventual improvement of services.

\section{Negotiation}

It has been shown in this report that the negotiation process, in its best form, is structured and can be analyzed. However, the five filters discussed above are neither absolute nor fixed. They provide a first pass at structuring a complex process. They appear to be valid at this state of investigation. Each filter, however, requires data, analysis, and testing. They could be, for example, further broken down, if it appears fruitful to do so, so that the more important elements could be better understood and utilized by information specialists in the future.

This approach to the negotiation process suggests ways by which library schools could re-examine course content in reference work. Is it possible, for example, to orient these courses more toward the dynamism of communication, i.e. negotiation, rather than concentrating solely on the static content of reference collections and classification systems? The former has been slighted, if considered at all, in the emphasis on the latter, the static approach. A newer approach should mean, for example, more attention to the social dynamics of definable parts of the population of library users, both actual and potential. This approach is already included in the training of children's librarians. It implies the total pattern of publishing, formal and informal communication, sociology, dissemination and professional education, if any, at whatever level of society a course is presumed relevant, from the "culturally deprived" to the "scientifically sophisticated."

A third result of this concern with the negotiation process is an understanding of the difference between a command and a question. A command assumes either (or both) of two things on the part of the inquirer. First, he knows exactly what he wants and can describe its form (book, paper, etc.) and its label (author and title). The second assumption is that the inquirer knows the functional organization of the system, the "rules of the game." It has been the argument of this paper that only the first assumption may be valid. The second assumption, with some exceptions, is not valid.

\section{Self-HelP}

It is obvious that librarians and information specialists are unable, physically, to handle the present demands on their services, let alone potential user demand. It is equally obvious that, as a communication channel, libraries are frustrating and complex systems to use. The previous section implied that a different type of education for librarians might make 
them more efficient in serving their various publics. That is, they could help more people. Such a course would by no means be sufficient to nullify the selfhelp process, even if we wanted to. Do we then wish to duplicate reference negotiation? Duplication of such a complex process is obviously impossible now. In spite of the glittering but distant potential of artificial intelligence, problem solving, and theorem-proving systems, the nature of print and other media may in fact require different approaches than those of human negotiation. There do appear to be several elements of the negotiation process worth investigating to see if mechanical systems might be feasible and useful.

Certainly substantive definition is one of these processes. Present subject naming systems however appear to be more concerned with the description of physical objects (books, papers, etc.), than assistance to the user in defining his subject. This is an important and critical differentiation, for present systems are object-oriented (static) rather than inquiry-oriented (dynamic). This is related directly to the concept of feedback -presentation to the user of various levels of display requiring a response from him. The inquirer's response in turn guides, alters, or limits future displays, searches, and answers by the system. However, most important in the process of subject definition is the display to the inquirer of alternatives, with specification of what these alternatives mean, where they lead to.

A second element or negotiation filter relevant to self-help is the inquirer's description of what he anticipates as an answer. Is it quantitative? descriptive? review? What is the level of sophistication? The very brief dialogue reported by one student in describing his search illustrates this process.

She began to look in a book of mathematical tables, and I explained to her that she would not find "Gaussian Curvature" there. I told her it was a theory, not a measurement. Whereupon she gave me a mathematical dictionary which looked as if it would help.

The important part of this process is that the user must be presented with choices, which match his type of anticipated answer with the forms available in the system. ${ }^{20}$

A third relevant filter is the process of translating from the inquirer s terminology to system terminology. The idea here of course is to allow the inquirer as much latitude as possible in describing his need $\left(Q_{3}\right.$ or even $\left.Q_{2}\right)$, and then funneling these into system terms $\left(Q_{4}\right)$.

The remaining two elements of the negotiation process probably cannot at present be built into the self-help process. However it may be possible at a primitive level to interrogate the user about the objective of his inquiry, what the information is to be used for. Using the ELIZA program developed by Project $\mathrm{MAC}^{21}$ or a related system presently being devised by James Green of Lehigh University, ${ }^{22}$ it is possible to extract from such questions as "What do you intend to do with this information?" additional concepts, phrases, and terms which would aid in specifying the subject. As such it may have a therapeutic effect on the inquirer, forcing him to define, limit, and analyze his inquiry, even though the system itself is not sophisticated enough to do much with the information in response to such questions.

The background or status of the inquirer does not appear to have much relevance to the self-help process, except as it may serve to determine a level of sophistication in the displays presented to him or in the answer delivered.

\footnotetext{
${ }^{20} \mathrm{It}$ is worth noting that the form divisions in the Dewey Classification anticipated this kind of approach.

${ }^{21} \mathrm{~J}$. Weizenhaum, "ELIZA, a Computer Program for the Study of Natural Language Communication," ACM Communications, IX (January 1966), 36-45.

${ }_{22}$ J. S. Green, op. cit.
} 


\section{Possible Systems and Devices}

All present systems have forms and elements intended to aid the inquirer: see also and see references; broader term, related term, and narrower term; form division in classification; generic relationships in classification. As more research goes into these sophisticated and often intricate mechanisms, the more the inquirer must turn to the information specialist. As was implied earlier, these are librarian's tools and appear to have little relevance-in their present formfor the inquirer. The system that is best able to display itself in a useful and functional way for the inquirer will be the most effective. Like information itself, the system that provides ease of access, specifically physical convenience, will be more effective than those concerned only with the quality of the scheme of subject organization. Video, film, microform, and computer media offer a tremendous array of possibilities hardly touched for interactive systems at the operating, i.e. public, level. Even at the elementary level of description of collection and its physical arrangement, very little has been done to direct the user to areas of concern to him.

General instruction in the use of library and information systems is presently normally accomplished by tours, formal instruction, and handbooks, none of which are available when the user actually has an inquiry. One of the more interesting systems presently under development is the Videosonic system at Mt. San Antonio College. ${ }^{23}$ Controlled experiment with these devices indicates that students who utilized the system used the library more effectively and sought services from the staff less frequently than those not exposed.

The Recordak Lodestar Microfilm Reader-Printer with an Image Control Keyboard offers several possibilities for

\footnotetext{
${ }^{23}$ Harriet Genung, "Can Machines Teach the Use of the Library?” CRL, XXVIII (January 1967), 25-30.
}

a programed learning and interrogating system relevant to the library. Each of approximately twenty-five hundred frames on a reel are available by dialing, or otherwise signifying an address on the keyboard. Michael B. Liebowitz of Lehigh University has done a preliminary design study ${ }^{24}$ for such a microfilm system in the field of metallurgy. In the system the user moves from index frames to subject network frames, then to bibliography, tables of contents, or data, as his needs indicate. The important part of this process is that the user is led through the system not in serial fashion, but by his area of interest as he responds to questions. He can also obtain hard copy as he moves along. There are some grave limitations in such microfilm systems. Updating for example becomes difficult, without redesigning an entire reel. However, the display of subject maps may allow a user a much better understanding of the relationship of his inquiry to terms within the system and to the interrelationships among terms. The presentation of tables of contents in this form may allow a user to scan quickly a summary of the contents of a specialized reference collection.

The study now underway at the graduate library school of the University of Chicago on the format, information, and public use of data on catalog cards ${ }^{25}$ may indicate more effective display of bibliographic information. The augmented catalog, now being experimented on by Project INTREX (21), will include such important forms of display as reviews and tables of contents. Although both of these developments will influence the display of information, they appear to be related more to command rather than to question. The work by

${ }^{24}$ Michael B. Leibowitz, A Proposed System for Displaying Accessing Techniques to Library Users in the Field of Metallurgy (M.S. Thesis, Lehigh University, 1967).

${ }^{25}$ University of Chicago. Graduate Library School. Requirements Study for Future Catalogs, Progress Report No. 1, October 1966. 
Engelbart and others at the Stanford Research Institute ${ }^{26}$ on the augmentation of human intellect by computers may generate interesting systems sometime in the future, but appears to have little pertinence at this time to the problems under consideration here.

If nothing else it is hoped that this first pass at the analysis of negotiation, both by human intermediaries and by self-help, may induce libraries and librarians to become critically aware of their role in this process. The advent of the MARC project, commercial processing of library materials, and the gradual disappearance of local cataloging operations will have a profound influence on operating libraries. It will become increasingly important for librarians to become interpreters and guides, developing both negotiation skills and displays for users of all levels of sophistication.

The contrast between the "wholesaler" and "retailer" of information may serve as an analogy here. However much they like to think otherwise, most libraries are "wholesalers" of knowledge, and the library is a warehouse (however grand the Gothic windows or beautiful the new carpeting) from which gobs of knowledge are indiscriminately doled out to whom ever happens to be captive of the system at that moment. There are exceptions-and they are noble ones.

\footnotetext{
${ }^{26}$ R. S. Taylor, op. cit.
}

Certainly most of the librarians who gave their time for this study are helping to make their libraries "retailers." This is the difference between the supermarket or discount house and the local dealer who takes pride in serving his customers, i.e. public. $\mathrm{He}$ is not pushing merchandise. He is matching a customer and his merchandise.

If libraries, at any level of service, are going to grow and evolve (and indeed exist) as integral parts of our urban technico-scientific culture, then they must know themselves. They must know themselves both as local and rather special institutions and as parts of very large, very dynamic, and very complex information and communications networks, which operate on both a formal and an informal level.

It may be, as someone has said of formal education, that the storage media which libraries handle are noise in the system. The real education and communication may take place outside or on the periphery of libraries and formal education. Indeed it may be that the reference interview, the negotiation of questions is the only process in libraries that is not noise. For it is through negotiation that an inquirer presumably resolves his problem, begins to understand what he means, and begins to adjust his question to both system and substantive noise in the store of recorded knowledge called the library.

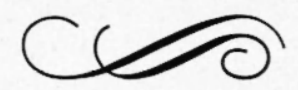

